Research Article

\title{
Multiobjective Optimization of a Hybrid Wind/Solar Battery Energy System in the Arctic
}

\author{
Thanh-Tuan Nguyen and Tobias Boström (iD \\ Department of Physics and Technology, UiT The Arctic University of Norway, Tromsø, Norway \\ Correspondence should be addressed to Tobias Boström; tobias.bostrom@uit.no
}

Received 3 August 2020; Revised 27 March 2021; Accepted 4 April 2021; Published 30 April 2021

Academic Editor: M. Huang

Copyright (C) 2021 Thanh-Tuan Nguyen and Tobias Boström. This is an open access article distributed under the Creative Commons Attribution License, which permits unrestricted use, distribution, and reproduction in any medium, provided the original work is properly cited.

\begin{abstract}
This paper presents an optimal design of a hybrid wind turbine/PV/battery energy system for a household application using a multiobjective optimization approach, namely, particle swarm optimization (PSO). The ultimately optimal component selection of the hybrid renewable energy system (HRES) is suggested by comprehensively investigating the effects of various factors on the cost-reliability relation, such as the mounting orientation, temperature on the PV modules, wind turbine hub height, different types of batteries, and different load profiles. The optimization results show the feasibility of HRES for a single-family household demand in the arctic region of Tromsø, Norway. As we will discuss in the results, an HRES operating in such a region can achieve great energy-autonomous levels at a reasonable cost partially thanks to the cold climate. The mounting structure and temperature effects on the PV modules and the battery type can significantly change the system performance in terms of cost and reliability, while a higher wind turbine hub offers little improvement. The result suggests an optimal HRES consisting of a wind turbine with a swept area of $21 \mathrm{~m}^{2}$ and a hub height of $12 \mathrm{~m}$, a PV system of $12 \mathrm{~m}^{2}$ with 2 -axis tracking, and a battery bank of $3 \mathrm{kWh}$. This system will achieve $98.2 \%$ in self-reliance. Assuming that the system lifetime is 20 years, the annual cost is about 900 USD. Even though this study focuses on an HRES for a single-family application in the arctic, such an approach can be extended for other applications and in other geographical areas.
\end{abstract}

\section{Introduction}

The use of renewable energy devices is environmentally benign and can in most situations replace fossil energy usage. Benefiting from government incentives and public support, the share of renewable energy production has been increasing rapidly in recent years [1]. It is also worth mentioning that the recent developments of supportive technologies (such as batteries and semiconductor devices) have also contributed to a decrease in cost and an increase in stability of new renewable energy systems, thereby making them more attractive to consumers. Among all new renewable energy technologies, wind and solar energy are the most widely used technologies because they are mature and cost-effective and both resources are available practically anywhere on Earth.

Solar and wind energy, however, have one fundamental issue that disheartens consumers: the intermittent characteristics. Both photovoltaic (PV) cells and wind turbines (WT) convert natural resources into electrical energy, but their outputs are highly dependent on the actual availability of resources. This dependence severely affects the reliability of the renewable energy system (RES). To mitigate and even eliminate the output fluctuation of the RES, energy storage units are usually employed as summarized by Khare et al. in [2]. The integration of energy storage into RES, unfortunately, leads to a cost increase of the system. The capacity of the storage system is determined based on the peak load demand, and it becomes considerably larger for a standalone RES since several margin hours are required. Therefore, it is necessary to optimize the components of the RES to meet the load demands with minimum cost and high reliability.

Sizing components of a standalone hybrid renewable energy system (HRES) is a challenging task. Compromises between its capacity to deliver at all times (reliability) and 
cost have to be made. An optimal sizing method is required to minimize the cost while ensuring the reliability of the system under the intermittent generation of renewable energy sources. Sizing components of a hybrid renewable system will directly affect its energy reliability and cost-effectiveness. Oversizing components can improve the system performance but does also result in an increased cost, hence reducing the cost-effectiveness of the system and vice versa. Unfortunately, the system reliability and cost-effectiveness are conflicting objectives, implying that an improvement of one objective can result in an inevitable degradation of the other. Therefore, an optimization problem arises to optimally size its components and to find the best compromise between them. The optimization result can help the decision-maker to determine a desired tradeoff among the design objectives with different preferences.

Many studies have carried out optimal sizing of an autonomous HRES. In a research paper, Ekren and Ekren introduced a statistical and mathematical method called response surface metamodels (RSM) to obtain the relation between the system cost and the system components [3]. Another study by Traore proposed a method for optimal sizing of wind/solar off-grid microgrid system using an enhanced genetic algorithm (GA) in [4]. In recent years, swarm intelligence-based optimization algorithms, e.g., particle swarm optimization (PSO), have been widely used in size optimization of hybrid systems or microgrids due to its simplicity and good convergence. Sawle et al. implemented both GA and PSO algorithm for optimal planning of a PVwind-biomass system with energy storage and a backup diesel generator in [5]. The result suggests that PSO is more efficient for planning of HRES than GA. Since the PSO can be extended for multicriteria problems, it provides users with the flexibility to customize the problem constraint that fits any specific requirements. In another study, Mohamed et al. proposed an optimal sizing method for HRES to maximize the energy generation and meet the load consumption at optimal cost and reliability considering smart grid load management algorithm [6]. Wang and Singh further utilized the PSO algorithm for optimal sizing of hybrid power system by considering multiple criteria including cost, reliability, and emission in [7].

Most of the mentioned studies focus on optimal sizing components of HRES with multiple objectives, e.g., cost, reliability, and emission. Very few of them considered the sensitivity of system parameters that could considerably change the design performances, such as solar irradiation and wind speed conditions. Furthermore, none of the studies has been conducted for HRES in harsh weather conditions like in the artic, where the temperature, solar irradiation, and wind speed could be extreme. Those extreme conditions can, in practice, happen simultaneously. Therefore, optimal sizing of an HRES in this region requires a new approach, found in this publication.

In this paper, a PSO-based optimization algorithm is applied for sizing components of an HRES in an arctic region. Because of the extreme site, at $69^{\circ} \mathrm{N}$ latitude, the system of interest will experience harsh working conditions. The system will be subjected to low-density horizontal solar irradiation, midnight sun in the summer, and no sun at all for two months. Furthermore, the cold temperatures give rise to a higher air density which is positive for wind power. Cold temperature is also positive for PV since the efficiency of standard silicon PV panels increases by about $0.5 \%$ per one-degree lower temperature as investigated by Dubey et al. in [8]. The harsh conditions at $69^{\circ} \mathrm{N}$ require special consideration when installing a wind and/or solar power system. For the PV system, a significant increase in power production can be obtained by mounting the panels at an optimum tilt angle or by adding a 1- or 2-axis tracking system that points the panels directly to the sun. PV systems installed at high latitudes receive the greatest benefit from a tracking system as reported by Huld et al. in [9].

To provide a fair assessment of standalone HRES at high latitudes, this study performs an optimal component sizing considering the effects of costs, PV system mounting angle, addition of a PV tracking system, wind turbine hub height, and cold temperatures.

\section{Input Data for Optimal Component Sizing of a Hybrid Wind/Solar Energy System}

To solve the optimization problem of component sizing for a hybrid wind/solar energy system, reliable datasets of wind speed, solar irradiation, and load consumption are required. The fundamental wind speed and irradiation data were acquired at meteorological station and used to estimate the power generation of the hybrid energy system. The load demand data was generated by a stochastic load model, which realistically can reproduce different household loads over days and seasons. This load model was developed by Widén et al. in $[10,11]$. In the following sections, these data are described in detail.

2.1. Weather Data. The case study for this application is an HRES installed in Tromsø, Norway, located at latitude $69^{\circ} \mathrm{N}$. The weather data for Tromsø are measured at the Holt meteorological station provided by the Agriculture Meteorological Service (Landbruksmeteorologisk Tjeneste, LMT), Bioforsk, to provide scientific data for weather forecast as well as research [12]. The wind measurements are performed by anemometers at the height of two meters above the ground. The data from Holt is chosen because the station is located at an open terrain with primarily laminar flow, making the collected data reliable. The global irradiation, which is the sum of the direct and diffuse radiation, is measured by a pyranometer on a horizontal surface. The instruments used at all Bioforsk's weather stations are either of the type CM11 or of the type CM3 from Kipp \& Zonen for the global irradiation and anemometers from Vector or Friedrichs for the wind measurements [13]. The data used in this study were collected during the year 2015 and averaged over 60 minutes to obtain hourly values.

Tromsø is located above the Arctic Circle and experiences a subarctic climate. The winter is dark as the sun is not visible from November 21 to January 21, so an energy generation system based solely on PV cannot be used. 
Instead, a wind turbine can be used or a combination of PV and a wind turbine. The wind potential during the winter is higher and compensates for the lack of solar energy to some extent. Daylight becomes long between the equinoxes, and the midnight sun appears from May 21 to July 21. This is an advantage for a PV system installed in this area in addition to the cold temperature effect which naturally boosts silicon module efficiencies with a factor of $0.5 \% \mathrm{~K}^{-1}$ based on research by Kleven in [14]. Furthermore, lower temperatures mean higher air densities, which is positive for wind power generation. The average summer temperature in Tromsø approximates $5.9^{\circ} \mathrm{C}[15]$. When estimating the power production of a PV system in regions with snow cover for a significant period of the year, normally from November to April, the reflection albedo effect which increases the solar energy generation is worth considering. Bifacial PV panels and tracking systems are also effective solutions for utilizing reflected energy from snow surfaces and the 360-degree revolving sun path during summer.

For a hybrid wind-solar system, an anticorrelation of wind and solar resources is preferred. An investigation of solar and wind correlation in Tromsø was done by Solbakken et al. in [13]. The results show that the correlation coefficient for hourly values is so weak that no conclusion can be drawn about the relationship between solar and wind power. However, for longer timescales, monthly, the correlation coefficient becomes negative with increased magnitudes indicating a stronger complementary characteristic of wind and solar power in Tromsø.

The wind data at the Holt station is measured at the altitude of two meters above ground, which needs to be extrapolated to estimate the actual wind speed at the altitude of the wind turbine hub. The vertical distribution of wind speed can be estimated using this logarithmic expression:

$$
v_{h}=v_{\text {ref }} \frac{\ln \left(h / z_{0}\right)}{\ln \left(h_{\text {ref }} / z_{0}\right)},
$$

where $v_{h}$ is the wind speed at a certain height $(\mathrm{m} / \mathrm{s}), v_{\text {ref }}$ is the reference wind speed measured at a reference height $(\mathrm{m} / \mathrm{s}), h$ is the height for $v_{h}, h_{\text {ref }}$ is the reference height, and $z_{0}$ is the roughness length in the current wind direction. The roughness length is the distance above ground level where the wind speed theoretically should be zero and it varies with landscape type. A landscape with many trees and tall buildings has long roughness length, while the water surface and completely open terrain with a smooth surface have a near-zero length. The Holt weather station is located at an open terrain with some scattered houses and trees; therefore, the landscape is categorized in roughness class 1.5 with a roughness length of $0.055 \mathrm{~m}$. The common heights of a small-scale wind turbine hub are $9 \mathrm{~m}, 12 \mathrm{~m}$, or $15 \mathrm{~m}$, and the effect of wind turbine hub height will be studied in this paper.

2.2. Stochastic Load Model. The stochastic load model developed by Widén et al. is used for the generation of domestic load demand data for the optimization problem $[10,11]$. The model offers high flexibility in selecting the load profiles for various applications while retaining all key features in empirically measured data, including end-use composition, diurnal and annual variation of the total demand and individual end-user, and demand variation over different time scales in individual households. The details on the stochastic load model can be described as follows.

The model framework can be split into two successive steps. First, it generates synthetic activity patterns for each household member using the Markov chain model. Each member can be assigned to one of the three states that are "absent," "present and active," and "present and inactive" at each discrete time step. The Markov chain model also defines the list activities of which a person in the house performs one at each time step. These activities are away, sleeping, cooking, dishwashing, washing, watching TV, using a computer, using audio devices, and others. When the time step changes, there is a transition possibility of the person from the current state to another, including the possibility of staying in the same state. Using these assumptions, the activity pattern for each member of the household is generated to be used in the second step. In this step, each activity in the Markov chain model corresponds to different electricity end-uses that are prescribed. The timing of the appliance load is complicated since it varies differently for specific appliances. Additionally, the sharing of appliances such as dishwashing, washing, or cooking and the operation mode of each appliance add more complexity to the model. Considering all the factors, the model converts the activity patterns into electrical consumption. The load demands reproduced by the model were successfully validated by comparing it to an empirical dataset and are therefore valid to use as inputs for the optimization problem [10].

For the investigation of the hybrid energy system, two load profiles for a detached house, one with 5 people and the other with 3 people, were generated. From the load model, it is observed that the detached house with 5 people consumes $6300 \mathrm{kWh}$ a year while the other's consumption is $4380 \mathrm{kWh}$. Those consumption amounts are approximate to the typical yearly consumption of a Norwegian household. It should be noted that this electricity consumption excludes energy for heating purposes. Heating could and should be supplied via another low exergy energy source such as bioenergy.

\subsection{Modeling of Hybrid Renewable Energy System} Components. In this section, mathematical models of the wind turbine, the PV modules, and the batteries, which are used for formulating the optimization problem, are discussed.

2.3.1. Wind Turbine Model. For a given wind turbine, its generated power varies with the wind speed that sweeps its rotor blades. The power generation is also proportional to the swept area of the blades, air density, and energy conversion efficiency. Hence, it is given by 


$$
P_{\mathrm{WT}}(t)=\left\{\begin{array}{ll}
0 & v(t)<v_{c i} \text { or } v(t)>v_{c o} \\
0.5 \rho v^{3} A_{\mathrm{WT}} \eta_{\mathrm{WT}} \eta_{\mathrm{Conv} W T} & \nu_{c i}<v(t)<v_{r a} \\
P_{\text {rated }} A_{\mathrm{WT}} \eta_{\mathrm{WT}} \eta_{\mathrm{Conv} W T} & \nu_{r a}<v(t)<v_{c o}
\end{array},\right.
$$

where $P_{\text {rated }}$ is the rated power of the WT $(\mathrm{kW}) ; \rho$ is air density $\left(\mathrm{kg} / \mathrm{m}^{3}\right) ; A_{\mathrm{WT}}$ is the swept area of the wind turbine $\left(\mathrm{m}^{2}\right) ; v$ is the wind speed at time $t(\mathrm{~m} / \mathrm{s}) ; v_{c i}, v_{r a}$, and $v_{c o}$ are the cut-in wind speed, rated wind speed, and cut-out wind speed $(\mathrm{m} / \mathrm{s})$, respectively; and $\eta_{\mathrm{WT}}$ and $\eta_{\mathrm{Conv}}$ are the efficiency of the WT and converters associated with it. The air density is a function of temperature and pressure expressed as

$$
\rho=\frac{p}{R_{\text {specific }} T}
$$

where $\rho$ is the air density $\left(\mathrm{kg} / \mathrm{m}^{3}\right), p$ is the absolute pressure $(\mathrm{Pa}), T$ is the absolute temperature $(\mathrm{K})$, and $R_{\text {specific }}$ is a specific gas constant for dry air (J/kg.K). A cold temperature increases the air density, thereby increasing the energy production of the wind turbine.

It has been proven that, for any wind-driven generator, the maximum factor of 0.59 of the theoretical energy can be extracted from the wind potential regardless of the turbine parameters. In practical design, due to the deficiency in mechanical electrical energy losses and electrical energy conversion losses, the efficiency of a WT is degraded further to a normal efficiency of $30 \%$ to $35 \%$.

2.3.2. Photovoltaic Array Model. Based on the irradiation data and the specification of a PV system, its output power can be estimated by the following equation:

$$
P_{\mathrm{PV}}(t)=G(t) A_{\mathrm{PV}} \eta_{\mathrm{PV}} \eta_{\mathrm{Con}},
$$

where $G(t)$ is the global inclined irradiation $\left(\mathrm{kW} / \mathrm{m}^{2}\right) ; A_{\mathrm{PV}}$ is the PV area $\left(m^{2}\right) ; \eta_{\mathrm{PV}}$ is the PV efficiency, and $\eta_{\mathrm{Con}}$ is the conversion efficiency of the power converter. The inclined irradiation $G(t)$ is estimated from the horizontal irradiation as in the following equation [16]:

$$
G(t)=H(t) \frac{\sin (\alpha+\beta)}{\sin \alpha}+H(t) \rho_{g}\left(\frac{1-\cos \beta}{2}\right),
$$

where $H(t)$ is the horizontal irradiation at time $t, \beta$ is the tilt angle of the PV panel, $\rho_{g}$ is the ground reflectance (albedo), and $\alpha$ is the sun elevation angle which can be calculated by $\alpha=90-\varphi+\delta(\varphi$ is the latitude of the PV panel site; $\delta$ is the declination angle). The declination angle is calculated as follows:

$$
\delta=23.45^{\circ} \sin \left[\frac{360}{365}(d+284)\right]
$$

where $d$ is the day of the year with January 1 as $d=1$.

In Tromsø, the albedo index significantly varies over the year, which is estimated to be 0.8 from November to March,
0.5 in April, 0.2 from May to September, and 0.4 in October, respectively. These albedo values are estimated by the authors' knowledge from living in this region for a decade.

To obtain optimal irradiation on the surface of a fixed PV panel, its tilt angle $\beta$ is chosen based on the latitude of the installation site. The optimal tilt angle for PV panels installed in the northern parts of Scandinavia ranges from 40 to $90^{\circ}$. Higher angles are needed not only to match the low standing sun but also because snow slides off at higher inclinations easier. Even wall-mounted panels can be advantageous in some locations.

Solar cell parameters are sensitive to temperature, and the parameter that is most affected by the temperature is the open-circuit voltage. Variation in the open-circuit voltage, in turn, affects the cell efficiency. As the temperature decreases, the cell efficiency increases with a factor of around $0.5 \% \mathrm{C}^{-1}$ [8]. It should be noted that the cell or module efficiency claimed by the manufacturer is tested under the standard testing conditions $\left(25^{\circ} \mathrm{C}, \mathrm{AM} 1.5\right.$, and $\left.1000 \mathrm{~W} / \mathrm{m}^{2}\right)$.

The estimation of the cell efficiency requires knowing the surface temperature of the PV cells. Modeling the cell's surface temperature or the module surface temperature is a challenging task, and it is not in the scope of this study. Therefore, the authors suggest a simple method to estimate the module surface temperature based on the ambient temperature measured at Holt weather station and the increased temperature on the surface of a module due to the solar irradiance. This observation has been conducted on a PV system at UiT in Tromsø, Norway, for three years, and it suggests that the module temperature is almost unchanged if the solar irradiance is less than $200 \mathrm{~W} / \mathrm{m}^{2}$. The module temperature increase is around $5^{\circ} \mathrm{C}, 10^{\circ} \mathrm{C}$, and $20^{\circ} \mathrm{C}$ when the radiation density is $200-400 \mathrm{~W} / \mathrm{m}^{2}, 400-600 \mathrm{~W} / \mathrm{m}^{2}$, and above $600 \mathrm{~W} / \mathrm{m}^{2}$, respectively. The real temperature mentioned later in this paper refers to the module surface temperature estimated using this proposed method.

2.3.3. Battery Model. Lead-acid batteries have commonly been used for renewable energy systems since its cost used to be more affordable as compared to that of other types of batteries such as Li-ion batteries. However, the price of Liion batteries is rapidly decreasing, making them more competitive with conventional battery technology as summarized by Curry in [17]. For any battery-based application, knowing the current capacity of a battery in use is important since it represents how much energy can be discharged to supply the load. The State-of-Charge (SOC) is defined as follows [7].

$$
\operatorname{SOC}(t)=\operatorname{SOC}(t-1) \pm \frac{P_{\mathrm{BT}}(t)}{V_{\mathrm{BT}}(t)} \Delta t,
$$

where $\operatorname{SOC}(t)$ and $\operatorname{SOC}(t-1)$ are the current and previous SOC of the battery, respectively; $P_{\text {bat }}(t)$ is the power charge/ discharge of the battery at time $t$ (the sign "+" when the battery is charged and "-" when it is discharged); and $V_{\mathrm{BT}}(t)$ is the battery voltage. 
2.4. Optimization Problem Formulation and Its Constraints. By formulating and solving an optimization problem for the system design stage, we aim at finding the best combination of the renewable source specifications, that is, photovoltaic array area $\left(A_{\mathrm{PV}}\right)$, wind turbine swept area $\left(A_{\mathrm{WT}}\right)$, and battery nominal capacity $\left(C_{\mathrm{BT}}\right)$ based on the sets of weather and power consumption data achieved through a year. To obtain a high reliability, the data is acquired hourly; therefore, the number of data points in each set is 365 (days) $\times 24$ (hours) $=8760$ (hours).

2.4.1. Objective Function. Multiple objectives can be defined to design an HRES such as cost, reliability, and emission. However, in this study, the system reliability and cost consideration are the primary objectives used for system design.

(1) Objective 1. Self-Reliance Due to the intermittence of renewable energy sources, the self-reliance of the hybrid system is considered as the most important objective in the design process. To measure the reliability of a hybrid system, the energy index of self-reliance (EISR) is introduced and it is calculated as follows [7]:

$$
\mathrm{EISR}=1-\mathrm{UME},
$$

where UME is the total unmet energy which can be calculated by (6) and it should be minimized.

$$
\mathrm{UME}=\frac{\sum_{t=1}^{T}\left(P_{\mathrm{BT} \min }+P_{d}(t)-P_{\mathrm{WT}}(t)-P_{\mathrm{PV}}(t)-P_{\mathrm{SOC}}(t)\right)}{E},
$$

where $T$ is the operational duration under consideration $(T=8760 \mathrm{~h}) ; P_{\mathrm{WT}}(t), P_{\mathrm{PV}}(t), P_{\mathrm{SOC}}(t)$, and $P_{d}(t)$ are the wind power, solar power, battery power, and demand at time $t$; $P_{\text {batmin }}$ is the minimum power that should be maintained in the battery (limited at 20\% SOC); and $E$ is the yearly energy demand.

(2) Objective 2. Cost The total cost of a hybrid system is the sum of the initial cost and the operation and maintenance cost, and it should be minimized [7].

$$
\operatorname{COST}=\frac{\sum_{i=\mathrm{WT}, \mathrm{PV}, \mathrm{BT}}\left(I_{i}+\mathrm{OM}_{i}\right)}{N_{p}},
$$

where $I_{i}$ is the installation cost for the equipment $i \mathrm{OM}_{i}$ is the operation and maintenance cost for the equipment $i$; and $N_{P}$ is the lifespan of system (20 years). Here, we assume that the lifespan of the system does not exceed the lifetime of both WT and PV (20 years). Due to this assumption, the initial costs of PV panels and WT are proportional to their cost per unit (USD/year) and size $\left(\mathrm{m}^{2}\right)$. The initial cost of the battery, however, depends also on its lifespan since the battery has shorter service time as compared to that of PV and WT components. To estimate the operation and maintenance cost, the interest and escalation rates are also considered [7].
For the PV panel:

The initial cost is

$$
I_{\mathrm{PV}}=\alpha_{\mathrm{PV}} A_{\mathrm{PV}}
$$

where $\alpha_{\mathrm{PV}}$ is the per-unit cost of $\mathrm{PV}\left(\mathrm{USD} / \mathrm{m}^{2}\right)$ and $A_{\mathrm{PV}}$ is the size of PV panels $\left(\mathrm{m}^{2}\right)$.

The operation and maintenance cost is

$$
\mathrm{OM}_{\mathrm{PV}}=\alpha_{\mathrm{OMPV}} A_{\mathrm{PV}} \sum_{i=1}^{N_{p}}\left(\frac{1+\gamma}{1+\gamma}\right)^{i}
$$

where $\alpha_{\mathrm{OMPV}}$ is the yearly per-unit cost of PV (USD/ year $\left./ \mathrm{m}^{2}\right), v$ is the escalation rate, and $\gamma$ is the interest rate.

For the WT generator:

The initial cost is

$$
I_{\mathrm{WT}}=\alpha_{\mathrm{WT}} A_{\mathrm{WT}} \text {, }
$$

where $\alpha_{\mathrm{WT}}$ is the per-unit-area cost of $\mathrm{WT}\left(\mathrm{USD} / \mathrm{m}^{2}\right)$ and $A_{\mathrm{WT}}$ is the size of the swept area $\left(\mathrm{m}^{2}\right)$.

The OM cost is

$$
\mathrm{OM}_{\mathrm{WT}}=\alpha_{\mathrm{OM}_{\mathrm{WT}}} A_{\mathrm{WT}} \sum_{i=1}^{N_{p}}\left(\frac{1+\gamma}{1+\gamma}\right)^{i}
$$

where $\alpha_{\text {OMWT }}$ is the yearly per-unit-area cost of WT (USD/year $\left./ \mathrm{m}^{2}\right), v$ is the escalation rate, and $\gamma$ is the interest rate.

For the battery storage:

The initial cost is

$$
I_{\mathrm{BT}}=\alpha_{\mathrm{BT}} P_{\mathrm{BT} \_\mathrm{CAP}} \sum_{i=1}^{X_{b}}\left(\frac{1+v}{1+\beta}\right)^{(1-i) N_{b}},
$$

where $\alpha_{\mathrm{BT}}$ is the per-unit-energy cost of WT (USD/ Wh), $P_{\text {BT_CAP }}$ is the nominal capacity of the battery bank (Wh), $X_{b}$ is the number of times of battery replacement, and $\beta$ is the inflation rate.

The OM cost is

$$
\mathrm{OM}_{\mathrm{BT}}=\alpha_{\mathrm{OM}_{\mathrm{BT}}} P_{\mathrm{BT}_{-} \mathrm{CAP}} \sum_{i=1}^{N_{p}}\left(\frac{1+\gamma}{1+\gamma}\right)^{i}
$$

The data used in the simulation program are given in Table 1 [7].

(3) Constraint Conditions. For any period, $t$, the total power of the system must supply load demand with certain reliability. Hence, we have 
TABLE 1: Data used in the simulation program.

\begin{tabular}{lc}
\hline Parameter & Value \\
\hline Lifespan of project $(N p)$ & 20 years \\
Lifespan of PV $\left(N_{\mathrm{PV}}\right)$ & 30 years \\
Lifespan of WT $\left(N_{\mathrm{WT}}\right)$ & 20 years \\
Lifespan of lead-acid battery at 50\% DOD $\left(N_{\text {bat }}\right)$ & 3 years \\
[18] & 12 years \\
Lifespan of Li-ion battery at $80 \%$ DOD $\left(N_{\text {bat }}\right)[18]$ & $32.75 \%$ \\
Efficiency of WT $\left(\eta_{\mathrm{WT}}\right)$ & $3.0 \mathrm{~m} / \mathrm{s}$ \\
Cut-in wind speed $\left(v_{c i}\right)$ & $22.0 \mathrm{~m} / \mathrm{s}$ \\
Cut-out wind speed $\left(v_{c o}\right)$ & $45.0 \mathrm{~m} / \mathrm{s}$ \\
Survival wind speed & $10.0 \mathrm{~m} / \mathrm{s}$ \\
Rated wind speed $\left(v_{r}\right)$ & $9 \%$ \\
Inflation rate $(\beta)$ & $12 \%$ \\
Interest rate $(\gamma)$ & $350 \mathrm{USD} / \mathrm{m}^{2}$ \\
PV panel price & $384 \mathrm{USD} / \mathrm{m}^{2}$ \\
WT price [7] & $100 \mathrm{USD} /$ \\
Lead-acid battery price $[7]$ & $\mathrm{kWh}$ \\
& $156 \mathrm{USD} /$ \\
Li-ion battery price $[17]$ & $\mathrm{kWh}$ \\
WT max. area $\left(A_{\mathrm{WTmax}}\right)$ & $30 \mathrm{~m}{ }^{2}$ \\
WT min. area $\left(A_{\mathrm{WTmin}}\right)$ & $1 \mathrm{~m} \mathrm{~m}^{2}$ \\
PV max. area $\left(A_{\mathrm{PV} \text { max }}\right)$ & $25 \mathrm{~m}{ }^{2}$ \\
PV min. area $\left(A_{\mathrm{PV} \text { max }}\right)$ & $1 \mathrm{~m}{ }^{2}$ \\
Battery max. capacity & $20 \mathrm{kWh}$ \\
Battery min. capacity & $1 \mathrm{kWh}$ \\
Converter eff. $\left(\eta_{\text {Conv }}\right)$ & $95 \%$ \\
Efficiency of PV $\left(\eta_{\mathrm{PV}}\right)$ & $21 \%$ \\
Optimum PV tilt angle $(\beta)$ & $65^{\circ}$ \\
Tromsø latitude & $69.4^{\circ} \mathrm{N}$ \\
\hline
\end{tabular}

$$
P_{\mathrm{WT}}(t)+P_{\mathrm{PV}}(t)+P_{\mathrm{BT}}(t) \geq(1-k) P_{d}(t),
$$

where $k$ is the ratio of the maximum permissible unmet power; $P_{\mathrm{WT}}(t), P_{\mathrm{PV}}(t), P_{\mathrm{bat}}(t)$, and $P_{d}(t)$ are the WT power, PV power, battery power, and power demand at $t$, respectively. Furthermore, the swept area of the WT, the area of the PV array, and battery's capacity should be within a certain range:

$$
\begin{aligned}
A_{\mathrm{WT} \text { min }} & \leq A_{\mathrm{WT}} \leq A_{\mathrm{WT} \max } \\
A_{\mathrm{PV} \min } & \leq A_{\mathrm{PV}} \leq A_{\mathrm{PV} \max } \\
C_{\mathrm{BT} \min } & \leq C_{\mathrm{BT}} \leq C_{\mathrm{BT} \max } .
\end{aligned}
$$

These size constraints are given in Table 1.

2.4.2. Optimization Algorithm. Particle swarm optimization (PSO), developed by Kennedy and Eberhart, is a computational intelligence-based technique that can be effectively applied to different optimization problems of power systems [19]. Assume that a swarm has $N$ particles and that $x$ and $v$ denote the particle position and its flying speed in the search space. Each particle of a swarm continuously records its best value achieved during the search. This value is called pbest while the best particle of the swarm is denoted by $g$ best. On each iteration, the current velocity of each particle is updated based on its current velocity, the particle's local information, and the global swarm information. The particle's position is then updated using the new particle's velocity.

$$
\begin{aligned}
v(t+1)= & w v(t)+c_{1} r_{1}(p \operatorname{best}(t)-x(t)) \\
& +c_{2} r_{2}(g \text { best }(t)-x(t)), \\
x(t+1)= & x(t)+v(t+1),
\end{aligned}
$$

where $t$ is the counter of generation; $w$ is the inertia weight factor; $c_{1}$ and $c_{2}$ are acceleration constants; $r_{1}$ and $r_{2}$ are the uniform random values in the range of $[0,1]$; and $v(t)$ and $x(t)$ are the velocity and position of the particle in generation $t$ (Algorithm 1).

To deal with multiobjective problems where individual objectives cannot be satisfied simultaneously, the conventional PSO has been modified to multiple-objective PSO (MOPSO) based on a Pareto front, and it can be described in the above pseudocode as presented by Coello et al. in $[20,21]$. Clearly, for multiobjective optimization, the solution is not a single solution. Instead, it gives a set of different nondominated solutions (the Pareto optimal set). There are three key issues when extending the conventional PSO algorithm for use in the multiobjective problem: (1) to select leader particles to be used as references to nondominated solutions; (2) to retain the nondominated solution over the search to report solutions that are nondominated to all the pass solutions; (3) to maintain the diversity in the swarm to avoid converging to a single solution.

\section{Results and Discussions}

The MOPSO optimization program was written and run in MATLAB software. To initiate the MOPSO algorithm, the number of particles in the swarm was set to be 70 particles and the maximum iteration was set to 50 . It should be noted that increasing the number of particles and iterations will affect the running time of the program. The total running time of each simulation on a standard desktop computer with the above configurations is 30 minutes. The execution time can be reduced by optimizing the weather data processing time and by introducing a stopping criterion for the optimization algorithm; however, this will be considered in future work.

The HRES in this study consists of a PV system, a wind turbine, and a battery bank, which need to be sized through the cost-reliability relationship. The PV panels correspond to commercial state-of-the-art products and have a standard testing condition (STC) efficiency of $21 \%$. A horizontal wind turbine is chosen because the horizontal type has a higher energy conversion efficiency compared to the vertical type. The storage elements of the system are lithium-ion (Li-ion) batteries. Despite their higher initial cost, Li-ion batteries show superior characteristics compared to the conventional lead-acid batteries. Moreover, if we take the cycle life and maintenance cost over the project lifetime into the analysis, the cost of the Li-ion batteries may be cheaper than that of the lead-acid batteries.

The following scenarios will be investigated for the optimal sizing problem of the hybrid renewable energy system: (1) a system with PV panels mounted at different 


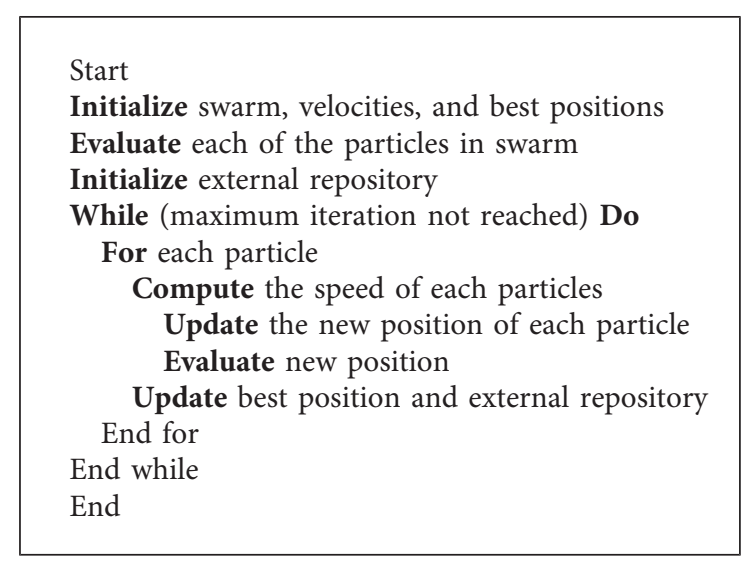

Algorithm 1: PSO algorithm pseudocode.

tilt angles: on a horizontal surface, at an optimum fixed tilt angle, and with an integrated two-axis tracking system; for these simulations, the wind turbine hub height is fixed to $12 \mathrm{~m}$ and batteries are Li-ion batteries; (2) a system with PV panels mounted at an optimum tilt angle, a wind turbine at $12 \mathrm{~m}$ hub height, and Li-ion batteries working under the standard testing conditions (STC) temperature $\left(25^{\circ} \mathrm{C}\right)$ and at real surface temperature; (3) a system with PV panels mounted at an optimum tilt angle, with Li-batteries and with the wind turbine installed at different hub heights; (4) a system with PV panels mounted at an optimum tilt angle, with a wind turbine at $12 \mathrm{~m}$ hub height but with different types of batteries: leadacid batteries and Li-ion batteries; (5) a system with PV panels mounted at an optimum tilt angle, with a wind turbine at $12 \mathrm{~m}$ hub height and Li-ion batteries but with varying load profiles.

\subsection{Case Study 1: The Effects of PV Modules Configuration on} the Cost-Reliability Relationship of the Hybrid Renewable System. Figure 1 represents the simulation results (Pareto fronts) of the optimal sizing problem for a hybrid system connected to a detached house with different tilt angles of PV panels: PV panels mounted on a horizontal surface, at a fixed optimum angle toward the south, and on a twoaxis tracking system. The hybrid energy system uses Liion batteries as storage devices. The wind turbine hub height is $12 \mathrm{~m}$ above ground. The module surface temperatures are estimated based on measured data from the Holt weather station. As discussed previously, due to its high latitude at $69.4^{\circ} \mathrm{N}$, Tromsø receives poor solar irradiation on a horizontal surface. Therefore, in practice, it is always recommended that the PV panels are mounted at a high tilt angle to maximize the available energy generation. For Tromsø area, the optimum tilt angle is around $65^{\circ}$ [14]. In the result, from top to bottom are the cost-reliability curves for the cases when the PV modules are mounted horizontally, the PV is mounted at an optimal fixed tilt angle, and the hybrid system has a 2 -axis tracking system, respectively. The curve on top indicates the worst case while the one at the bottom represents the

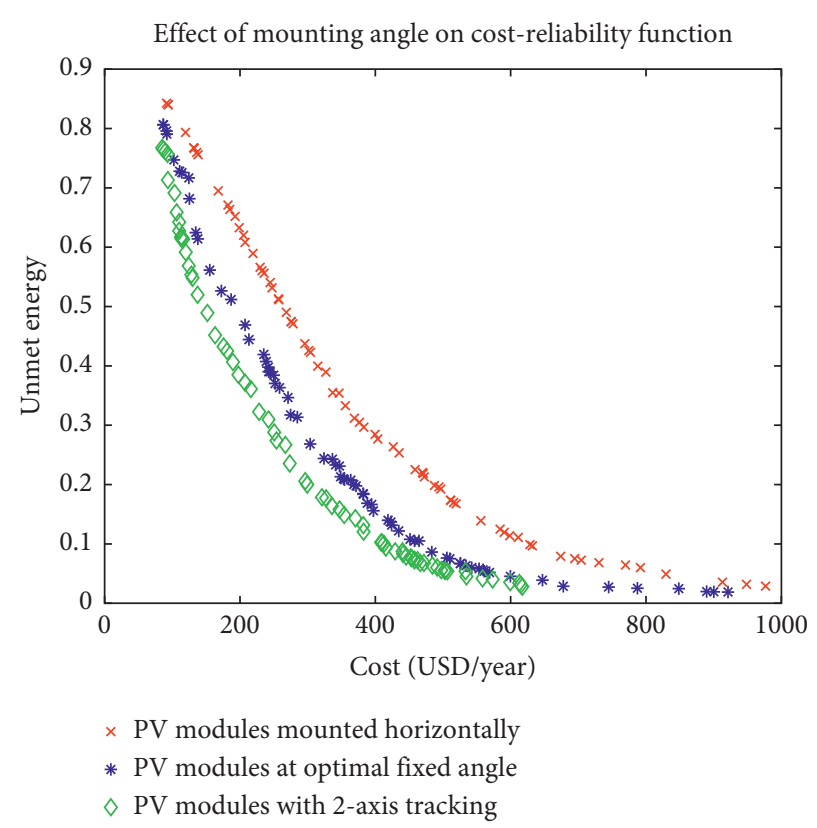

FIGURE 1: The cost-reliability curves of a hybrid wind/solar system for a detached house of 5 people with different tilt angles of PV panels (wind turbine hub height: $12 \mathrm{~m}$; battery type: Li-ion batteries; using measured weather data from Holt; yearly consumption: $6300 \mathrm{kWh}$ ).

best case. This is obvious since the PV modules mounted horizontally receive less solar irradiance than the other cases do.

The effect of the tilt angle of the PV system can be seen in Figure 1 . The cost-reliability curves show that the hybrid system with PV panels mounted at a fixed optimum angle toward the south is close to self-reliance $(1.8 \%$ of unmet energy) at the cost of USD 921 per year. This cost includes the initial cost and the operation and maintenance cost per year over the lifetime of the hybrid system (assumed to be 20 years in this study). In the case of the same system with PV panels installed horizontally, at the same cost, the mismatch energy increases to $3.5 \%$ a year. The difference becomes obvious when the cost reduces; for example, at the cost of USD 600 per year, the systems with PV modules mounted at optimal angle suffer much less energy mismatch compared to the system with horizontally mounted PV modules (3.5\% vs. $11.4 \%)$.

To further utilize the available solar resource, a two-axis tracking system can be utilized. The tracking systems continuously adjust the tilt angle of the PV panels so that they follow the path and always point directly to the sun. In this way, the PV panels capture the maximum possible daily radiation. Comprehensive studies on the effect of the tracking system for PV panels were discussed in $[9,14]$. For high-latitude areas, the relative energy gain of a two-axis tracking system compared to a fixed optimum angle system is about $40-50 \%$.

Integrating an axis tracking system into the PV system complicates the hybrid system with required electric motors, sun direction sensors, and control algorithms. This adds an increased cost not only in the installation but also in the 
operation and maintenance of the system. In general, Axaopoulos et al. stated that adding the two-axis tracking capability to a PV system leads to a $30 \%$ increase in the total cost [22-24]. This includes the installation cost and the maintenance cost of the tracking system. Considering the energy gain factor and the cost increase when adding a tracking system, the cost-reliability curve of the hybrid system with a two-axis tracking system is also illustrated in Figure 1.

At present, there are only a few two-axis tracking and fixed tilt angle PV systems installed at a similar high latitude [14]. However, a high-latitude region, where the solar irradiation density is low at a horizontal surface and the sun moves 360 degrees around the horizon, receives the greatest benefit from the two-axis tracking system. Consequently, a two-axis tracking system can be a promising solution for the development of solar energy in this region.

\subsection{Case Study 2: The Effects of Cold Temperatures on the Cost-} Reliability Relationship of the Hybrid Renewable System. In Troms $\varnothing$, the average temperature from February to October is $5.3^{\circ} \mathrm{C}$ (recorded for 2017). This anticipates a significant improvement of the PV production, hence the costreliability relationship. To achieve high accuracy, an hourly resolution of temperature data is used to estimate the variation of the cell's efficiency and the air density with the temperature.

The system configuration used in this case is identical to the system studied in case 1 with the PV mounted at $65^{\circ}$ toward south, wind turbine at $12 \mathrm{~m}$ height, and Li-ion batteries. Two temperature conditions are used: one at a standard temperature of $25^{\circ} \mathrm{C}$, and the other condition uses the real module temperature based on data recorded for 1 year at the Holt station. Both temperature conditions have the added module surface temperature increase, defined at the end of Section 3.2, embedded in the simulation. As can be seen in Figure 2, the curve displacement reveals a considerable impact of temperature where the cold temperatures naturally add significant improvement in the system performance.

\subsection{Case Study 3: The Effects of Wind Turbines Hub Heights on} the Cost-Reliability Relationship of the Hybrid Renewable System. The impact of the windmill's tower height is also investigated in this paper. Due to the difference between the anemometer and the windmill hub's altitude, the measured wind data is extrapolated to estimate the actual wind speed at the hub altitude using (1).

Figure 3 represents the simulation results for a hybrid energy system using Li-ion batteries connected to a detached house with three commonly used wind turbine hub heights ( $9 \mathrm{~m}, 12 \mathrm{~m}$, and $15 \mathrm{~m})$. The PV panels are mounted at a fixed tilt angle of $65^{\circ}$ toward the south in this case. The results show a small variation of the curves when the height difference is $3 \mathrm{~m}$. As the curves are only slightly different, it is suggested that the added cost of building extra height for the hub is not motivating.

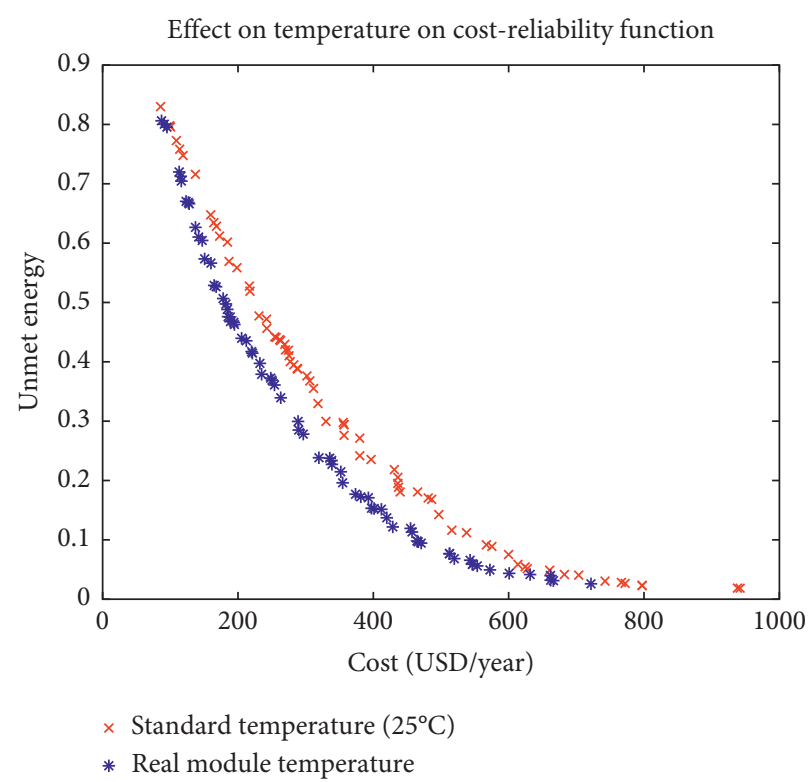

FIgURE 2: The effect of cold temperature on cost-reliability relationship of the hybrid wind/solar energy system for a detached house of 5 people (PV panels tilt angle: $65^{\circ}$ toward south; wind turbine hub height: $12 \mathrm{~m}$; battery type: Li-ion batteries; yearly consumption: $6300 \mathrm{kWh})$.

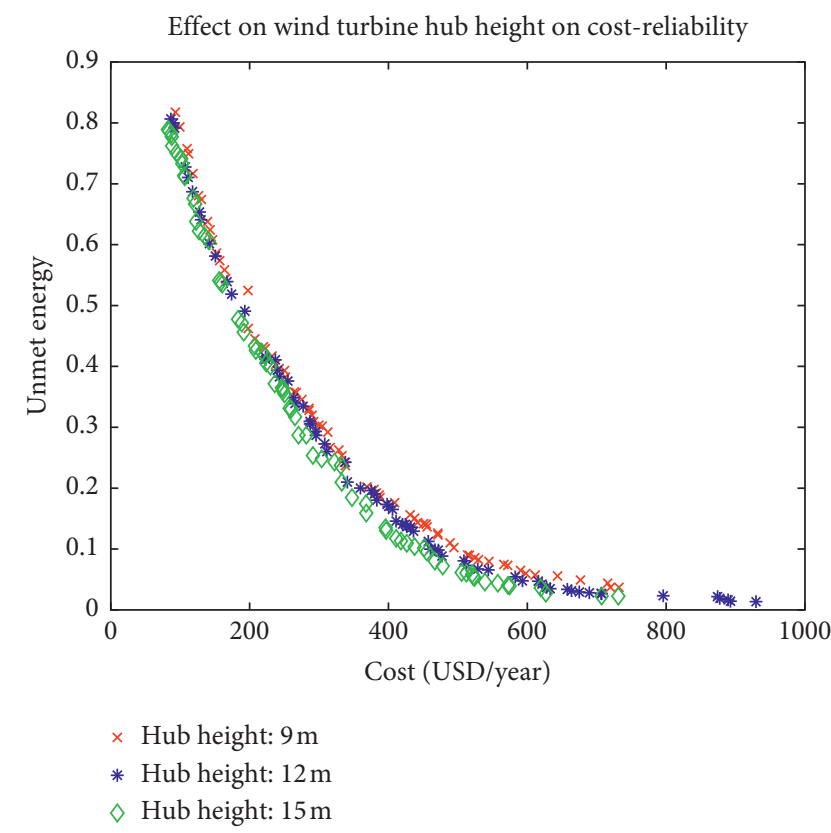

FIGURE 3: The effect of wind turbine height on cost-reliability relationships of a hybrid wind/solar energy system for a detached house of 5 people (PV panels tilt angle: $65^{\circ}$ toward the south; battery type: Li-ion batteries; using measured weather data from Holt; yearly consumption: $6300 \mathrm{kWh}$ ).

3.4. Case Study 4: The Effects of Battery Types on the CostReliability Relationship of the Hybrid Renewable System. Lead-acid batteries have been commonly used as the storage devices of hybrid renewable energy systems. However, lithium-based batteries have become increasingly common 
in various applications due to the affordability. Li-ion batteries offer higher depth of discharge (DOD) and cycle life energy capacity than lead-acid batteries. A typical lead-acid battery lasts for 1000 to 1200 cycles at 50\% DOD, a rate which is heavily influenced by the operating conditions, while a Li-ion battery has an average cycle life of 2,000 at 80\% DOD [17]. The Li-ion batteries are also lighter with the weight of one-third lead-acid batteries at the same capacity. Therefore, when calculating the cost of the energy storage system, it is important to consider the expense for shipping, installation, and maintenance, along with the initial cost of the battery. Since Li-ion batteries do not require regular maintenance and have a significantly higher cycle life, the cost for lead-acid batteries may be higher in the long run when considering the lifetime cost of each energy source.

The foregoing anticipation is proven by simulation, and the results are shown in Figure 4. The simulation parameters for this simulation are also given in Table 1 with the initial cost of the lead-acid battery being USD 100/kWh and that of the Li-ion battery being USD 156/kWh. Additionally, the PV panels are mounted at a fixed tilt angle of $65^{\circ}$ toward the south. The wind turbine hub height is $12 \mathrm{~m}$, and the temperature used is the measured data at Holt. As indeed seen, even though the initial cost of the Li-ion battery is significantly higher than that of the lead-acid battery, its cycle life, cost of maintenance, and energy capacity compensate for the initial cost and make the hybrid system with Li-ion batteries significantly cheaper than the one using lead-acid batteries. At about USD 900 per year, the optimal system employs a $2.9 \mathrm{kWh}$ Li-ion battery bank and has only $1.8 \%$ annual unmet energy. Correspondingly, the system with a lead-acid battery needs a capacity of $3.5 \mathrm{kWh}$. The lead-acid batterybased system also suffers a significant energy deficiency of $18.3 \%$ of the annual energy demand.

3.5. Case Study 5: The Effects of Load Profiles on the CostReliability Relationship of the Hybrid Renewable System. The last factor of which the effect on the cost-reliability curve of the hybrid wind/solar system is shown in Figure 5 is the load profile. To examine the impact of the load patterns on the system performance, the same system configuration studied in Figure 1 that used a detached house load with 5 people is also simulated here for a decreased load with only 3 people. As the load demand decreases in the case of the house with 3 occupants, the cost and thus the size of the hybrid energy system are considerably reduced (observe that the $y$-axis starts at -0.3 in Figure 5). In terms of reliability, from the cost of about USD 230, the system starts generating excessive energy that might need an optimal using strategy, for example, pumping the abundant energy to the grid, curtailment, or changing the load pattern.

As previously discussed in the stochastic load model, the activity pattern greatly depends on user behaviors. Therefore, users may change their habit of using appliances in the household to reduce the load demand, thereby reducing the size and cost of the hybrid renewable system.

Table 2 provides quantitative configurations of the hybrid energy systems studied previously, where System 1 is the

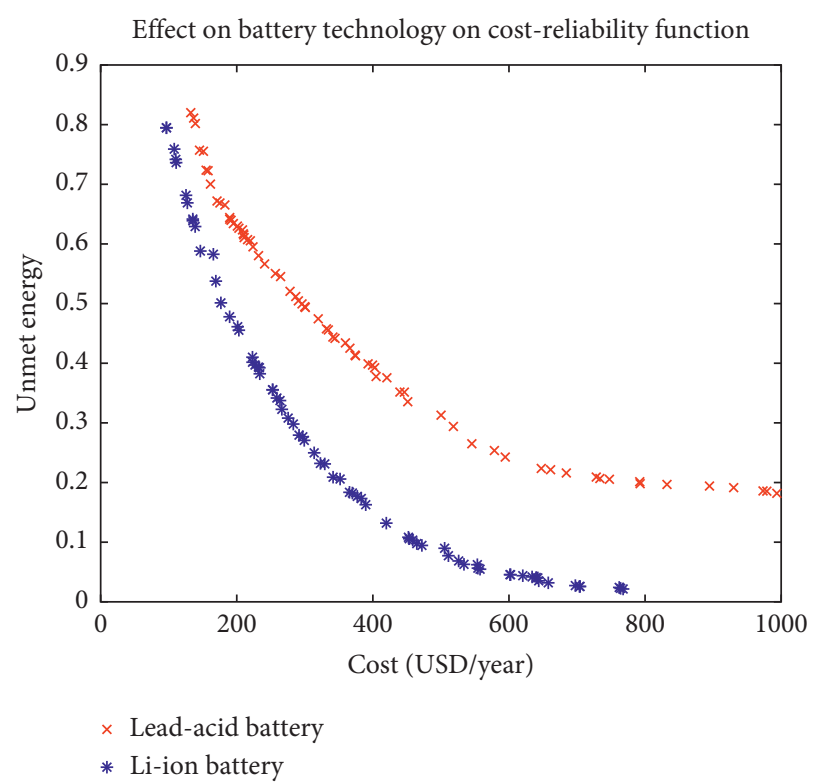

Figure 4: The effect of battery types on the cost-reliability relationship of a hybrid wind/solar system developed for a detached house of 5 people (PV panels, tilt angle: $65^{\circ}$ toward south; wind turbine hub height: $12 \mathrm{~m}$; using measured weather data from Holt; yearly consumption: $6300 \mathrm{kWh}$ ).

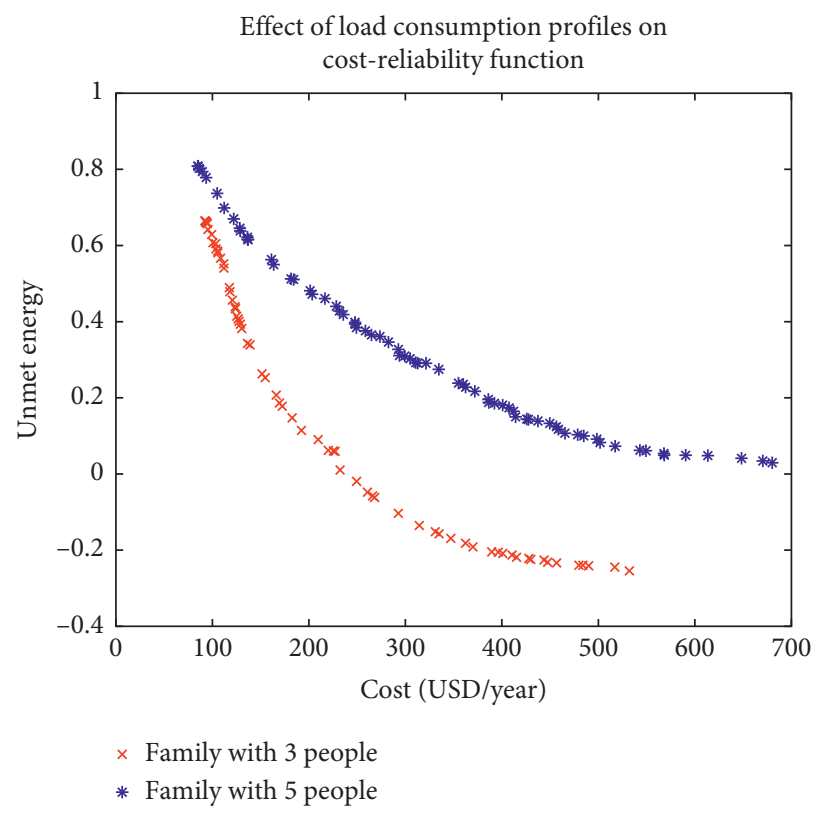

FIGURE 5: The cost-reliability comparison of two identical systems connected to different households (PV panels tilt angle: $65^{\circ}$ toward south; wind turbine hub height: $12 \mathrm{~m}$; battery type: Li-ion batteries; using measured weather data from Holt).

hybrid energy system with PV panels mounted at $65^{\circ}$ south, wind turbine height of $12 \mathrm{~m}$, and Li-ion batteries (Figure 1); System 2 shares the same configurations of wind turbine and batteries with System 1, but the PV panels have two-axis tracking systems (Figure 1); and System 3 shares the same configurations of wind turbine and PV panels with System 1, 
TABLE 2: Illustrative system configurations for various hybrid renewable energy systems from the component optimal sizing results.

\begin{tabular}{|c|c|c|c|c|c|c|}
\hline & Config. options & Cost/year (USD) & Unmet energy (\%) & WT swept area $\left(\mathrm{m}^{2}\right)$ & $\mathrm{PV}$ area $\left(\mathrm{m}^{2}\right)$ & Bat. capacity (kWh) \\
\hline \multirow{3}{*}{ System 1} & Opt1.1 & 921 & 1.8 & 21.2 & 11.6 & 2.9 \\
\hline & Opt1.2 & 791 & 6.0 & 19.7 & 10.2 & 2.9 \\
\hline & Opt1.3 & 632 & 9.6 & 17.9 & 9.8 & 2.9 \\
\hline \multirow{3}{*}{ System 2} & Opt2.1 & 900 & 3.2 & 21.2 & 10.6 & 3.0 \\
\hline & Opt2.2 & 617 & 2.7 & 17.9 & 7.1 & 3.0 \\
\hline & Opt2.3 & 469 & 9.8 & 13.5 & 6.5 & 2.8 \\
\hline \multirow{3}{*}{ System 3} & Opt3.1 & 993 & 18.2 & 24.3 & 11.0 & 3.5 \\
\hline & Opt3.2 & 491 & 33.5 & 11.7 & 6.0 & 2.3 \\
\hline & Opt3.3 & 399 & 39.9 & 8.3 & 4.5 & 2.4 \\
\hline
\end{tabular}

These design options provide a useful suggestion when selecting components for hybrid wind/solar energy system. Depending on the design objectives, the most suitable option can be chosen accordingly.

TABLE 3: Result comparison by the proposed method and HOMER software.

\begin{tabular}{lccccc}
\hline & Cost (\$/year) & Unmet energy $(\%)$ & WT swept area $\left(\mathrm{m}^{2}\right)$ & PV area $\left(\mathrm{m}^{2}\right)$ & Bat. capacity $(\mathrm{kWh})$ \\
\hline Proposed method & 469 & 9.8 & 13.5 & 6.5 & 2.8 \\
HOMER & 494 & 5.0 & 12.6 & 6.4 & 3 \\
\hline
\end{tabular}

but with lead-acid batteries (Figure 4). The measured weather data from Holt have been used in all the three cases.

From the simulation results, each system is quantified with 3 design options that consist of the wind turbine swept area, the PV area, the battery capacity, and its corresponding cost and reliability (unmet energy).

Bifacial PV technology should also be investigated since it adds a $10-15 \%$ increase in yearly production as observed from testing an existing PV system in Tromsø. In this study, only 1 year of weather and load data were used. To improve the simulation results, longer datasets should be used, and it will also be studied in future work.

3.6. Validation of Proposed Method. To verify the optimization results, an as identical as possible system to System 2 in Table 2 was built and run in the HOMER software [25]. The measured global horizontal irradiance, wind speed, and temperature from the Holt meteorological station were imported as inputs to HOMER. The load profile generated by the stochastic load model for a detached house of 5 people was also imported to the HOMER simulation. The simulation results by HOMER are given in Table 3 .

As can be seen from Table 3, the simulation results by the proposed method and the HOMER software closely match, validating the proposed method.

\section{Conclusions}

The study shows the important result that it is indeed feasible and cost-effective to install a standalone hybrid renewable energy system in an arctic region of Scandinavia to power a single-family house with electricity. The result is fascinating when putting into perspective the fact that the region is above the Arctic Circle with midwinter darkness at $69^{\circ} \mathrm{N}$ and experiences cold temperatures.

The paper represents a comprehensive study on the impact of various factors on component sizing of a hybrid wind/solar energy system using a multiobjective PSO algorithm. The result outlines the advantages of operating a hybrid wind/solar system in an arctic region and more importantly shows the feasibility of hybrid wind/PV systems in high-latitude regions in terms of economic concern and reliability. The optimal system costs about $900 \$$ per year, has $2 \%$ unmet energy per year, and consists of a $12 \mathrm{~m}^{2} \mathrm{PV}$ system, a $21 \mathrm{~m}^{2}$ wind power system, and a $3 \mathrm{kWh}$ battery storage system. The optimization parameter "unmet energy" is rarely used in related works. Having a system that is cost-effective but has $2 \%$ unmet energy is an interesting case. Two percent of the year represents 175 hours or about one week in time. These hours will not occur in a consecutive order but rather be spread out during a few occasions during the winter months. In our work, we have excluded heating from the simulation so the house and inhabitants can still be kept warm by using, for example, bioenergy. However, an interesting question remains; how many hours with no access to electricity can an off-grid house in the arctic accept? This question should be addressed in further cross-disciplinary studies.

In future work, the attained method can be applied to select the most suitable options among different system configurations and optimization targets or to find the best installation site for a hybrid renewable energy system.

\section{Data Availability}

The data used to support the study will be provided upon request to the corresponding author.

\section{Conflicts of Interest}

The authors declare that they have no conflicts of interest.

\section{Acknowledgments}

The authors would like to acknowledge RDA for funding the project 2012-0258, Renewable Energy Investment in the High North. 


\section{References}

[1] E. E. Agency, Renewable Energy in Europe 2017: Recent Growth and Knock-On Effects, Publications Office of the European Union, Luxembourg, 2017.

[2] V. Khare, S. Nema, and P. Baredar, "Solar-wind hybrid renewable energy system: a review," Renewable and Sustainable Energy Reviews, vol. 58, pp. 23-33, 2016.

[3] O. Ekren and B. Y. Ekren, "Size optimization of a PV/wind hybrid energy conversion system with battery storage using response surface methodology," Applied Energy, vol. 85, no. 11, pp. 1086-1101, 2008.

[4] A. Traoré, H. Elgothamy, and M. A. Zohdy, "Optimal sizing of solar/wind hybrid off-grid microgrids using an enhanced genetic algorithm," Journal of Power and Energy Engineering, vol. 6, no. 5, 2018.

[5] Y. Sawle, S. C. Gupta, and A. K. Bohre, "Optimal sizing of standalone PV/Wind/Biomass hybrid energy system using GA and PSO optimization technique," Energy Procedia, vol. 117, pp. 690-698, 2017.

[6] M. A. Mohamed, A. M. Eltamaly, and A. I. Alolah, "PSObased smart grid application for sizing and optimization of hybrid renewable energy systems," PLOS ONE, vol. 11, no. 8, Article ID e0159702, 2016.

[7] L. Wang and C. Singh, "Multicriteria design of hybrid power generation systems based on a modified particle swarm optimization algorithm," IEEE Transactions on Energy Conversion, vol. 24, no. 1, pp. 163-172, 2009.

[8] S. Dubey, J. N. Sarvaiya, and B. Seshadri, "Temperature dependent photovoltaic (PV) efficiency and its effect on PV production in the world-a review," Energy Procedia, vol. 33, pp. 311-321, 2013.

[9] T. Huld, M. Súri, and E. D. Dunlop, “Comparison of potential solar electricity output from fixed-inclined and two-axis tracking photovoltaic modules in Europe," Progress in Photovoltaics: Research and Applications, vol. 16, no. 1, pp. 47-59, 2007.

[10] J. Widén, A. M. Nilsson, and E. Wäckelgård, "A combined Markov-chain and bottom-up approach to modelling of domestic lighting demand," Energy and Buildings, vol. 41, no. 10, pp. 1001-1012, 2009.

[11] J. Widén and E. Wäckelgård, "A high-resolution stochastic model of domestic activity patterns and electricity demand," Applied Energy, vol. 87, no. 6, pp. 1880-1892, 2010.

[12] NIBIO, N. I. f.B., http://lmt.bioforsk.no/agrometbase/ getweatherdata.php.

[13] K. Solbakken, B. Babar, and T. Boström, "Correlation of wind and solar power in high-latitude arctic areas in Northern Norway and Svalbard," Renewable Energy and Environmental Sustainability, vol. 1, p. 42, 2016.

[14] Ø. Kleven, "Solar cells above the arctic circle-a comparison between a two-axis tracking system and simulations," in Proceedings of the 24th European Photovoltaic Solar Energy Conference, Hamburg, Germany, 2009.

[15] NRK and M., https://www.yr.no/place/Norway/Troms/Troms $\% \mathrm{C} 3 \% \mathrm{~B} 8 /$ Troms\%C3\%B8/statistics.html.

[16] PVEducation.

[17] C. Curry, Li-ion Battery Costs and Market: Squeesed Margins Seek Technology Improvements and New Business Models, 2017.

[18] G. Albright, J. Edie, and S. Al-Hallaj, Comparison of Lead Acid to Lithium-Ion in Stationary Storage Applications, AllCell Technologies LLC, Chicago, IL, USA, 2012.
[19] J. Kennedy and R. Eberhart, "Particle swarm optimization," in Proceedings of the IEEE International Conference on Neural Networks, Perth, Australia, 1995.

[20] C. A. C. Coello, G. T. Pulido, and M. S. Lechuga, "Handling multiple objectives with particle swarm optimization," IEEE Transactions on Evolutionary Computation, vol. 8, no. 3, pp. 256-279, 2004.

[21] Coello, C. A. C. CINVESTAV-IPN, http://delta.cs.cinvestav. $\mathrm{mx} / \sim$ ccoello/EMOO/emoopage.html.

[22] P. J. Axaopoulos and E. D. Fylladitakis, "Energy and economic comparative study of a tracking vs. a fixed photovoltaic system," European Scientific Journal, vol. 9, 2013.

[23] P. Wild, "The levelised cost of energy of three solar PV technologies installed at UQ gatton campus," in Proceedings of the Asia-Pacific Solar Research Conference, Canberra, Australia, December 2016.

[24] S. P. Singh, K. Srikant, and K. S. Jairaj, "Performance comparison and cost analysis of single Axis tracking and fixed tilt PV systems," in Proceedings of the International Conference on Current Trends in Engineering, Science and Technology, ICCTEST, Bangalore, India, 2017.

[25] HOMEREnergy, https://www.homerenergy.com/products/ pro/index.html. 